\title{
MAXILLARY ARCH DIMENSIONS CHANGES AFTER CORTICOTOMY ASSISTED SLOW MAXILLARY EXPANSION
}

\author{
Sherif S Morcos* and Tamer Abd El Bari Hamed**
}

\begin{abstract}
Objectives: To evaluate the maxillary arch dimensions changes occurring with corticotomy assisted Slow Maxillary Expansion (SME).

Materials and Methods: Sixteen patients (4 males and 12 females) requiring maxillary expansion (mean age:19 years; range: 14-24 years) were divided into two groups: Group A: included 10 patients subjected to buccal alveolar corticotomy before SME and Group B:included 6 patients who had only SME.CBCT images were taken at T1(before) and T2 (after). Arch perimeter (AP) and Arch depth (AD) as well as palatal vault height (PVH) were recorded. T-tests (paired, student) determined the significance performed to evaluate the effect of treatment within and between each group.
\end{abstract}

Results: The significant increase in AP by $2.26 \mathrm{~mm}$ in corticotomy group and $1.19 \mathrm{~mm}$ in control group, significant decrease in AD $-0.6 \mathrm{~mm}$ and $\mathbf{P V H}-0.92 \mathrm{~mm}$ immediatly post expansion in corticotomy group only.

Conclusions: Corticotomy assisted expansion produced a significant changes in arch dimensions

KEY WORDS: CBCT, Corticotomy, Dentoalveolar, SME

\section{INTRODUCTION}

Transverse maxillary hypoplasia is frequently seen in adolescents and adults. It always manifested in oral breathing patients causing some rhinologic and dentofacial problems such as decrease of the nasal permeability, bilateral dental maxillary crossbite and compromising esthetics, occlusal stability and normal mouth functioning ${ }^{[1]}$. Therefore, early treatment is necessary to establish craniofacial equilibrium ${ }^{[2]}$. Many approaches were used as a clinical routine to normalize the upper arch hypoplasia to achieve a stable and functional occlusion. The approaches differed by the frequency of the appliance activation, magnitude of the applied force, duration of treatment and patient age), Baccetti et al. explained how maxillary expansion before the pubertal peak showed significant and more stable long-term changes at the skeletal

* Lecturer, Orthodontic Dept. Faculty of Dentistry, Suez Canal University, Egypt.

** Assistant Professor Oral and Maxillofacial Surgery Dept, Suez Canal University, Egypt. 
level, and also the shift from the skeletal level to the dentoalveolar level if expansion is done after pubertal growth spurt ${ }^{[3]}$. This difficulty is due to the increase of inter-digitations between the maxillary suture processes which become strong and need a heavy force to separate the inter-digitated processes ${ }^{[4]}$ which is the source of difficulty in correction of maxillary constriction in a skeletally mature patients [5]. The conventional nonsurgical method of slow expansion used in adults has many complications as it become inefficient and takes longer time and might compromise periodontal health if done beyond a few millimeters ${ }^{[6]}$. The introduction of corticotomy assisted orthodontics provided new solutions to many limitations in the orthodontic treatment of adults.

Köle in 1959 concluded that the disrupting of continuity of the cortical layer of bone leads to moving segments of outlined blocks of bone to be moved more rapidly ${ }^{[7]}$. Wilcko et al. introduced the current technique named Accelerated Osteogenic Orthodontics (AOO) ${ }^{[8]}$ or Periodontally Accelerated Osteogenic Orthodontics (PAOO) ${ }^{[9]}$ to improve tooth movements and reduce treatment time via inducing cortical bone injury through linear cuttings (corticotomy) and then performing orthodontic treatment. Frost ${ }^{[10]}$ explained the reorganization activity and accelerated bone turnover at the surgical site due to bone injury and the subsequent intensity of its healing response and called it "Regional Acceleratory Phenomenon" (RAP) ${ }^{[11]}$. Corticotomy assisted expansion is considered an optimal way to treat mild to moderate maxillary transverse deficiency in adults .Studies about corticotomy assisted expansion like those done by Mossaz et al. ${ }^{[12]}$,Wilcko et al. ${ }^{\left[{ }^{[3]}\right.}$ and Hassan et al. ${ }^{[13]}$ showed the efficiency and safety of such technique in treatment of maxillary constriction and posterior crossbite either unilateral or bilateral in adult. The aim of this study is to evaluate the maxillary arch dimensions changes occurred with SME assisted with buccal alveolar corticotomy.

\section{MATERIALS AND METHODS}

Sixteen patients (12 females and 4 males) requiring maxillary expansion therapy as part of their comprehensive orthodontic treatment were included in this study. Patients were selected from the outpatient clinic of the orthodontic department; Faculty of Dentistry, Suez Canal University, Ismailia, Egypt. The mean age of patients was 19 years old ranging from (14-24 years). Inclusion criteria were the presence of transverse maxillary constriction with posterior crossbite or collapsed arch requiring maxillary expansion, minimum age 14 years old at the beginning of treatment. Exclusion criteria were craniofacial abnormality, presence of medical conditions which may interfere with surgery and having orthodontic appliances prior to the start of maxillary expansion. Adequate records were collected before treatment, which are dental and medical history, photos, study models, CBCT, and signed informed consent. Ten patients (two males and eight females) with a mean age of $19.3 \pm 2.91$ years were subjected to alveolar corticotomy 1 week before SME, and 6 patients (two males and four females) with a mean age of $18.1 \pm 3.76$ years had SME only. Coricotomy was done in the first group as a selective buccal alveolar corticotomy from the first premolar to the first molar mesial, distal, and apical) bilaterally according to the technique described by Murphy et al. ${ }^{[14]}$ (Figure1). Each patient had CBCT images taken prior to orthodontic treatment (T1) and immediately after the completion of maxillary expansion (T2) using Hygienic banded expansion appliances. Activation rate was 3 times per week with $1 / 4 \mathrm{~mm}$ change per turn until an adequate amount of over expansion achieved evaluated by clinical observation when the lingual cusps of upper molars become in touch with buccal cusps of lower molars, then the appliance replaced by a Trans Palatal Arch (TPA) with extended arms for at least 3 months after expansion for retention. Orthodontic treatment was continued with a full bonded straight wire preadjusted appliance. Imaging was carried out by Cranex 3D X-ray machine (Soredex, Tuusula, 
Finland) at $85 \mathrm{kVp}, 15 \mathrm{~mA}, 6 \mathrm{FOV}$, and 12.6 and manipulated by OnDemand 3D software (Build 1.0.9.1332, Cybermed, Seoul, Korea). To evaluate the immediate arch dimensions changes following SME, the following measurements were taken at $\mathrm{T} 1$ and $\mathrm{T} 2$.

Arch perimeter and arch length were measured on 3D reconstructed occlusal image and the following measurements were recorded.

- Arch Perimeter (AP): Measured as four segments from the mesial surface of upper right first molar to mesial surface of upper left first molar (Figure 2).

- Arch Depth (AD): Measured as a straight line from upper incisors midline perpendicular to a line joining the mesiobuccal cusp tips of the first molars (Figure 3).
Two-dimensional coronal images were created perpendicular to the midsagittal plane to measure the Arch depth in molar area.

- Palatal Vault Height (PVH): Measured as a straight line from mid sagittal plane perpendicular to a line joining the mesiopalatal cusp tips of the first molars (Figure 4).

\section{Statistical Analysis:}

Data presented as means and standard deviation (SD) values. Independent t-test used to study the difference between different Groups and. Dependent t-test used to compared between different follow-up priods within each group. Statistical analysis was performed with IBM ${ }^{\circledR}$ SPSS ${ }^{\circledR}$ (SPSS Inc., IBM Corporation, NY, USA) Statistics Version 22 for Windows.
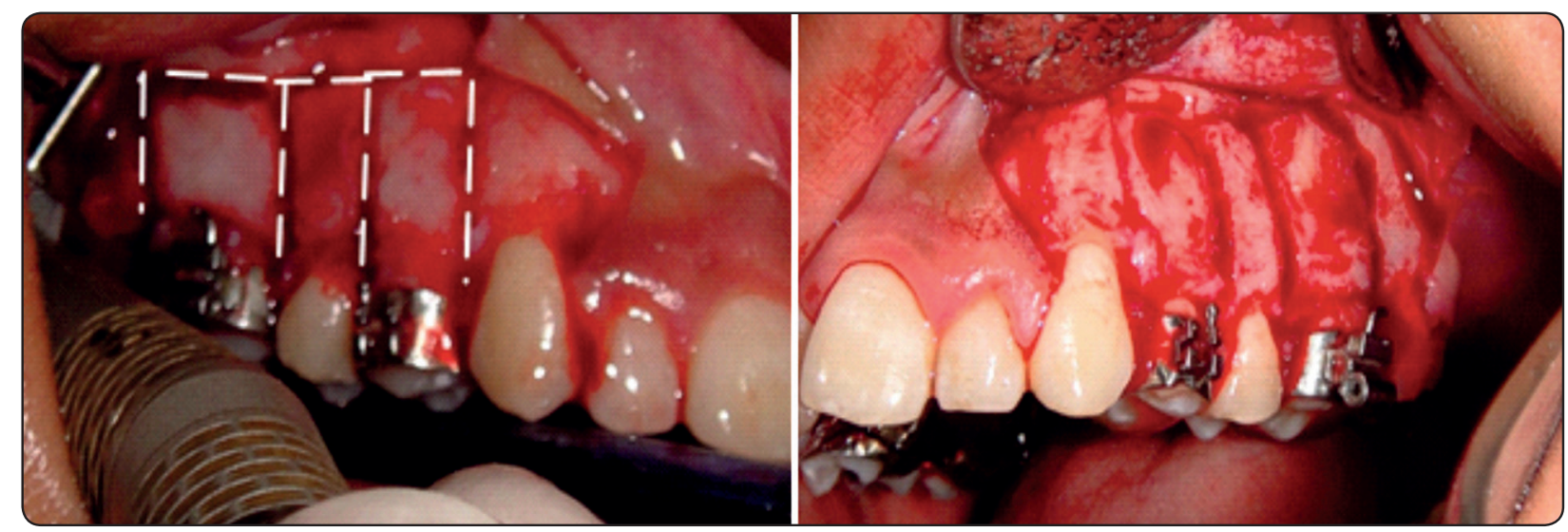

Fig. (1) Corticotomy.

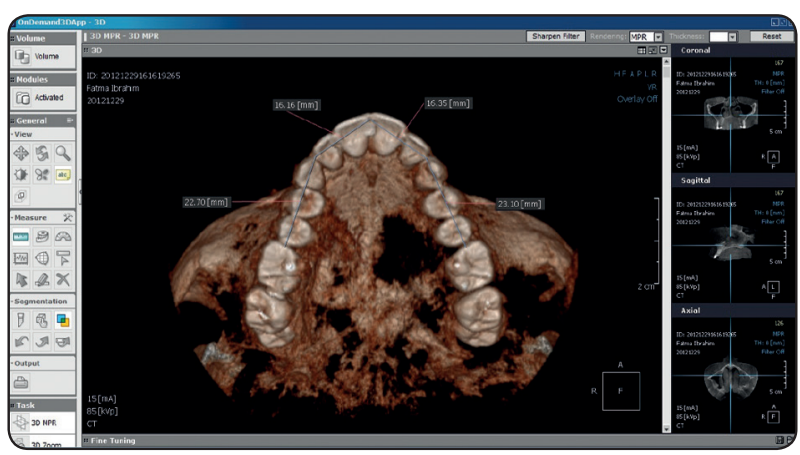

Fig. (2)Arch perimeter.

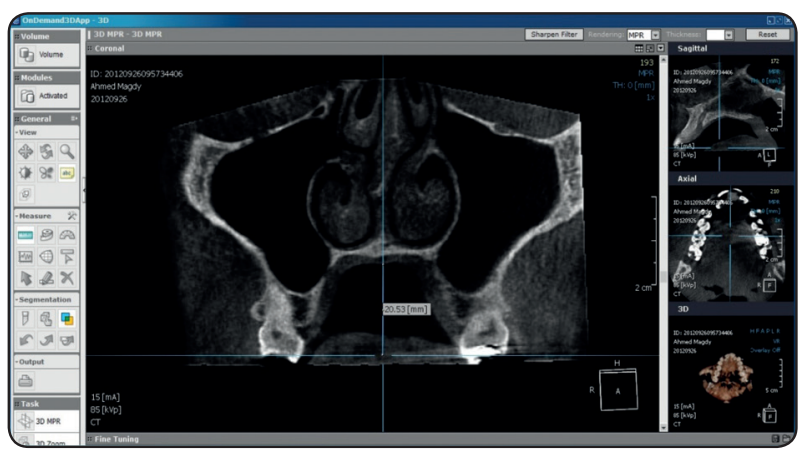

Fig. (3) Arch depth. 


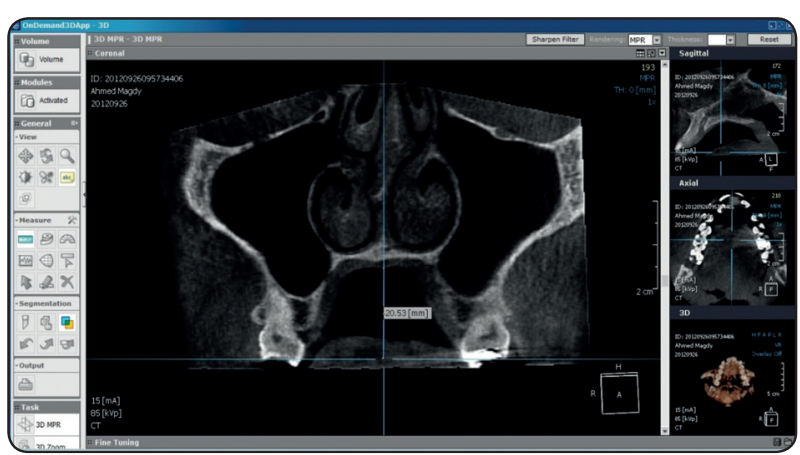

Fig. (4) Palatal vault height.

\section{RESULTS}

\section{Arch perimeter (AP)}

Results shown in table 1 and Fig. 5

TABLE (1) Mean and standard deviation (SD) of Arch perimeter for the different tested groups and follow-up periods:

\begin{tabular}{|c|c|c|c|c|c|}
\hline \multirow{2}{*}{} & \multicolumn{4}{|c|}{ Group } & \multirow{2}{*}{ p-value } \\
\cline { 2 - 5 } & \multicolumn{2}{|c|}{ Corticotomy } & \multicolumn{2}{c|}{ Control } & \\
\cline { 2 - 5 } & Mean & SD & Mean & SD & \\
\hline $\begin{array}{c}\text { Arch perimeter } \\
\text { (T1) }\end{array}$ & 73.24 & 3.75 & 75.63 & 3.27 & $\begin{array}{c}0.218 \\
\text { NS }\end{array}$ \\
\hline $\begin{array}{c}\text { Arch perimeter } \\
\text { (T2) }\end{array}$ & 75.50 & 3.65 & 76.82 & 4.07 & $\begin{array}{c}0.512 \\
\text { NS }\end{array}$ \\
\hline p-value & \multicolumn{2}{|c|}{$\leq 0.001 *$} & $0.045^{*}$ & \\
\hline
\end{tabular}

*= Significant $;$ NS= Non-significant

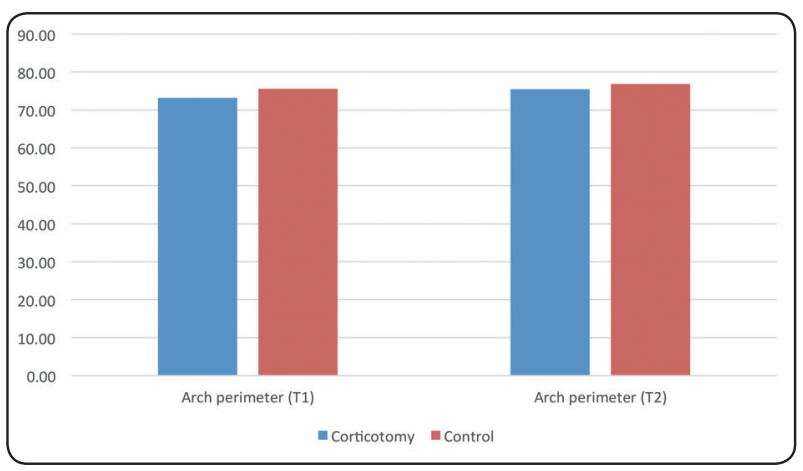

Fig. (5) Histogram showing the Mean Arch perimeter for the different tested groups.

\section{Difference between the tested groups:}

Corticotomy (73.24 \pm 3.75$)$ showed the lowest Arch perimeter compared to Control $(75.63 \pm 3.27)$ with an insignificant difference between each other's at $\mathrm{p}=0.218$ for $\mathrm{T} 1$.

Corticotomy (75.5 \pm 3.65$)$ showed the lowest Arch perimeter compared to Control $(76.82 \pm 4.07)$ with an insignificant difference between each other's at $\mathrm{p}=0.512$ for $\mathrm{T} 2$.

\section{Difference between the Follow-up periods:}

T1 (73.24 \pm 3.75$)$ showed the lowest Arch perimeter followed by a significant increase at $\mathrm{T} 2$ $(75.5 \pm 3.65)$ at $\mathrm{p} \leq 0.001$ for Corticotomy group.

T1 (75.63 \pm 3.27$)$ showed the lowest Arch perimeter followed by a significant increase at $\mathrm{T} 2$ (76.82 \pm 4.07$)$ at $\mathrm{p}=0.045$ for Control group.

\section{Arch depth (AD)}

Results shown in table 2 and Fig. 6

TABLE (2) Mean and standard deviation (SD) of Arch depth for the different tested groups and follow-up periods:

\begin{tabular}{|c|c|c|c|c|c|}
\hline & \multicolumn{4}{|c|}{ Group } & \multirow[t]{3}{*}{ p-value } \\
\hline & \multicolumn{2}{|c|}{ Corticotomy } & \multicolumn{2}{|c|}{ Control } & \\
\hline & Mean & $\mathrm{SD}$ & Mean & SD & \\
\hline Arch depth (T1) & 29.98 & 2.69 & 29.09 & 1.88 & $0.490 \mathrm{NS}$ \\
\hline Arch depth (T2) & 29.00 & 2.42 & 28.49 & 2.01 & $0.672 \mathrm{NS}$ \\
\hline p-value & \multicolumn{2}{|c|}{$\leq 0.001 *$} & \multicolumn{2}{|c|}{$0.056 \mathrm{NS}$} & \\
\hline
\end{tabular}

\section{*= Significant; $N S=$ Non-significant}

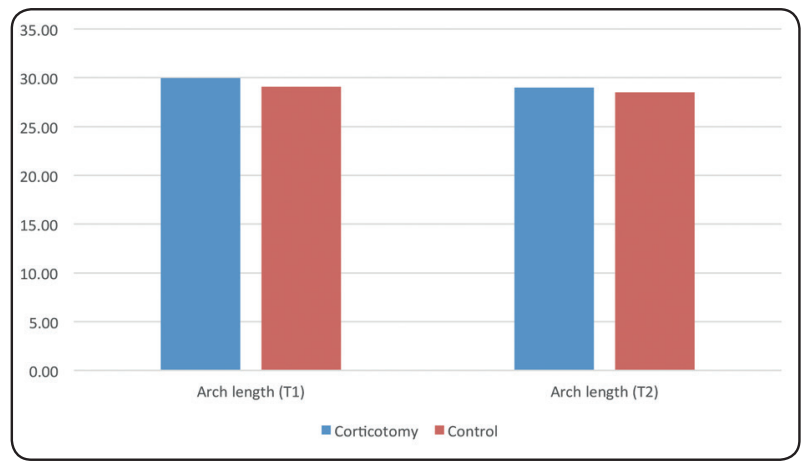

Fig. (6) Histogram showing the Mean Arch Length for the different tested groups. 


\section{Difference between the tested groups}

Corticotomy (29.98 \pm 2.69$)$ showed the highest Arch Length compared to Control $(29.09 \pm 1.88)$ with an insignificant difference between each other's at $\mathrm{p}=0.490$ for $\mathrm{T} 1$.

Corticotomy (29 \pm 2.42$)$ showed the highest Arch Length compared to Control (28.49 \pm 2.01$)$ with an insignificant difference between each other's at $\mathrm{p}=0.672$ for $\mathrm{T} 2$.

\section{Difference between the Follow-up periods}

T1 (29.98 \pm 2.69$)$ showed the highest Arch Length followed by a significant decrease at T2 $(29 \pm 2.42)$ at $\mathrm{p} \leq 0.001$ for Corticotomy group.

T1 (29.09 \pm 1.88$)$ showed the highest Arch Length followed by an insignificant decrease at $\mathrm{T} 2$ $(28.49 \pm 2.01)$ at $\mathrm{p}=0.056$ for Control group.

\section{Palatal vault Height (PVH)}

Results shown in table 3 and Fig. 7

TABLE (3) Mean and standard deviation (SD) of Palatal vault height for the different tested groups and follow-up periods:

\begin{tabular}{|c|c|c|c|c|c|}
\hline \multirow{2}{*}{} & \multicolumn{4}{|c|}{ Group } & \multirow{2}{*}{ p-value } \\
\cline { 2 - 5 } & Corticotomy & \multicolumn{2}{c|}{ Control } & \\
\cline { 2 - 5 } & Mean & SD & Mean & SD & \\
\hline $\begin{array}{c}\text { Palatal vault } \\
\text { height (T1) }\end{array}$ & 20.57 & 1.02 & 20.08 & 3.68 & $0.694 \mathrm{NS}$ \\
\hline $\begin{array}{c}\text { Palatal vault } \\
\text { height (T2) }\end{array}$ & 19.65 & 1.37 & 19.23 & 3.14 & $0.715 \mathrm{NS}$ \\
\hline p-value & \multicolumn{2}{|c|}{$0.002 *$} & \multicolumn{2}{|c|}{$0.112 \mathrm{NS}$} & \\
\hline
\end{tabular}

*= Significant $;$ NS= Non-significant

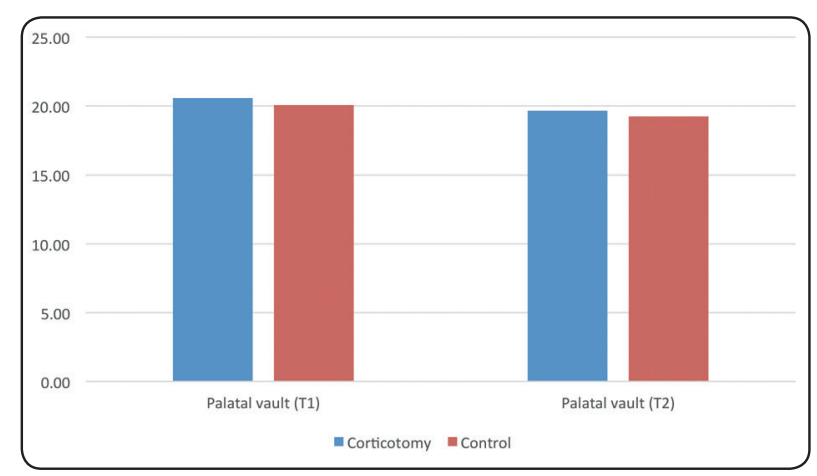

Fig. (7) Histogram showing the Mean Palatal vault for the different tested groups.

\section{Difference between the tested groups:}

Corticotomy $(20.57 \pm 1.02)$ showed the highest Palatal vault compared to Control $(20.08 \pm 3.68)$ with an insignificant difference between each other's at $\mathrm{p}=0.694$ for $\mathrm{T} 1$.

Corticotomy (19.65 \pm 1.37$)$ showed the highest Palatal vault compared to Control $(19.23 \pm 3.14)$ with an insignificant difference between each other's at $\mathrm{p}=0.715$ for $\mathrm{T} 2$.

\section{Difference between the Follow-up periods:}

T1 $(20.57 \pm 1.02)$ showed the highest Palatal vault followed by a significant decrease at $\mathrm{T} 2$ $(19.65 \pm 1.37)$ at $\mathrm{p}=0.002$ for Corticotomy group.

T1 $(20.08 \pm 3.68)$ showed the highest Palatal vault followed by an insignificant decrease at $\mathrm{T} 2$ $(19.23 \pm 3.14)$ at $\mathrm{p}=0.112$ for Control group.

\section{DISCUSSION}

The aim of the current study was to evaluate the maxillary arch dimensions changes after corticotomy assisted slow maxillary expansion

The results of the current study showed significant increase in Arch perimeter (AP) between $\mathrm{T}_{1}$ and $\mathrm{T}_{2}$ time points for both corticotomy and control groups.

Corticotomy group showed increase in AP about $2.26 \mathrm{~mm}$ at $\mathrm{P} \leq 0.001$, and control group showed increase in AP about $1.19 \mathrm{~mm}$ at $\mathrm{p}=0.045^{*}$, the increase of AP in corticotomy group was larger than control group by $1.7 \mathrm{~mm}$. These results show the effect of corticotomy in enhancing the efficiency of expansion in gaining space due to RAP phenomena. McNamara et al. ${ }^{[15]}$ reported a significant overall long-term gain in the maxillary arch perimeter (6 mm) who performed retrospective study on 112 RME treated patients followed by fixed appliance, according to Lagravere ${ }^{[16]}$ this gain could not be attributed exclusively to the RME procedure. Orthodontic treatment after the RME could have played a significant role in this regard. It is important 
to mention that the studies which results in different AP values was done in samples with younger mean age and with different methodology producing skeletal and dentoalveolar expansion rather than only dentoalveolar expansion produced in our study.

In the present study the (Arch depth) AD change in corticotomy group showed a significant decrease at $\mathrm{T} 2$ at $\mathrm{p} \leq 0.001$ by $-0.98 \mathrm{~mm}$ and insignificant decrease at $\mathrm{T} 2$ by $-0.6 \mathrm{~mm}$ at $\mathrm{p}=0.056$ in control group. The results of our study was not different with the results concluded by McNamara et al. ${ }^{[15]}$ how showed significant decrease between $\mathrm{T} 2$ and $\mathrm{T} 1$ by $-0.9 \mathrm{~mm}$ in $\mathrm{AD}$ immediately after treatment, also results by Spillane ${ }^{[17]}$ showed significant decrease in $\mathrm{AD}$ immediately after expansion, however there were no significant difference was recorded in the treated groups regarding changes in maxillary arch depth on long term evaluation ${ }^{[15,16,17]}$.

In our study the Palatal vault height (PVH) showed a significant decrease at T2 by $-0.92 \mathrm{~mm}$ at $\mathrm{p}=0.002$ for Corticotomy group and insignificant decrease at $\mathrm{T} 2$ by at $\mathrm{p}=0.112$ for Control group. Our results were resembling the results published by Spillane ${ }^{[17]}$ who found a significant decrease in palatal height by $-0.6 \mathrm{~mm}$ following RME in mixed dentition patients.

\section{CONCLUSIONS}

Based on the current study results, the corticotomy assisted expansion produced a significant changes in arch dimensions as following :

1- Arch perimeter increased by $2.26 \mathrm{~mm}$.

2- Arch depth decreased by $-0.6 \mathrm{~mm}$.

3- Palatal vault height decreased by $-0.92 \mathrm{~mm}$.

\section{REFERENCES}

1. McNamara J.A. Maxillary transverse deficiency. Am J Orthod Dentofacial Orthop 2000; 117(5):567-70.

2. Kanekawa M and Shimizu N. Age-related changes on bone regeneration in midpalatal suture during maxillary expansion in the rat. Am J Orthod Dentofacial Orthop. 1998; 114(6):646-53.
3. Baccetti T., Franchi L., Cameron C. G., and McNamara J. A. Jr.: Treatment timing for rapid maxillary expansion. Angle Orthod. 2001; 71(5):343-50.

4. Melsen B.:Palatal growth studied on human autopsy material. A histologic microradiographic study. Am J Orthod 1975; 68:42-54.

5. Lokesh Suria and Parul Tanejab: Surgically assisted rapid palatal expansion: A literature review. Am J Orthod Dentofacial Orthop 2008;133:290-302.

6. Vanarsdall R. L. Jr: Transverse dimension and long-term stability. Semin Orthod1999, 5:171-180.

7. Köle H.: Surgical operations of the alveolar ridge to correct occlusal abnormalities. Oral Surg Oral Med Oral Pathol 12:515-529, 1959.

8. Wilcko W. M., Wilcko T., Bouquot J. E., and Ferguson D. J.: Rapid orthodontics with alveolar reshaping: two case reports of decrowding. Int J Periodontics Restorative Dent 2001, 21:9-19.

9. Wilcko M. T., Bissada W. W., and Nabil F.: An EvidenceBased Analysis of Periodontally Accelerated Orthodontic and Osteogenic Techniques: A Synthesis of Scientific Perspectives. Semin Orthod2008, 14:305-316.

10. Frost H. M.: The regional accelerated phenomenon. Orthop Clin N Am 1981,12:725-726.

11. Yaffe A., Fine N., and Binderman I.: Regional accelerated phenomenon in the mandible following mucoperiosteal flap surgery. J Periodontol 1994, 65:79-83.

12. Mossaz C. F., Byloff F. K., and Richter M.:Unilateral and bilateral corticotomies for correction of maxillary transverse discrepancies. Eur J Orthod; 14 (2): 110-116, 1992.

13. Hassan A. H., AlGhamdi A. T., Al-Fraidi A. A., Al-Hubail A., and Hajrassy M. K.: Unilateral cross bite treated by corticotomy assisted expansion: two case reports. Head \& Face Medicine; 6:6, 2010.

14. Murphy K. G., Wilcko M. T., Wilcko W. M., and Ferguson D. J.: Periodontal accelerated osteogenic orthodontics: a description of the surgical technique. J Oral Maxillofac Surg 2009; 67:2160- 2166.

15. McNamara JA Jr, Baccetti T, Franchi L, Herberger TA. Rapid maxillary expansion followed by fixed appliances: a long-term evaluation of changes in arch dimensions. Angle Orthod. 2003;73:344-353.

16. Manuel O. Lagraver, Paul W. Major, Carlos Flores-Mir : Long-Term Dental Arch Changes After Rapid Maxillary Expansion Treatment: A Systematic Review . Angle Orthod 2005;75:155-161.

17. Spillane L.M., McNmara JA Jr. : Maxillary adaptation to expansion in the mixed dentition. Semin Orthod, 1995 sep; 1(3):176-87. 